\title{
Targeting sphingosine kinase I with LNA oligonucleotides in gastric
}

\section{cancer}

\author{
Thorsten Füreder ${ }^{1}$, Doris Hoeflmayer ${ }^{1}$, Bo Hansen ${ }^{2}$ and Volker Wacheck*1
}

\author{
Address: ${ }^{1}$ Department of Clinical Pharmacology, Medical University Vienna, 1090 Vienna, Austria and ${ }^{2}$ Santaris Pharma A/S, 2970 Hørsholm, \\ Denmark \\ Email: Volker Wacheck* - volker.wacheck@meduniwien.ac.at \\ * Corresponding author
}

from 14th Scientific Symposium of the Austrian Pharmacological Society (APHAR)

Innsbruck, Austria. 2I-22 November 2008

Published: 5 November 2008

BMC Pharmacology 2008, 8(Suppl I):A5I doi:I0.||86/|47|-22|0-8-SI-A5 I

This abstract is available from: http://www.biomedcentral.com/I47I-22I0/8/SI/A5I

(c) 2008 Füreder et al; licensee BioMed Central Ltd.

\section{Background}

Gastric cancer is the fourth most common cancer worldwide. Despite advances in diagnosis of gastric cancer, the prognosis at advanced stage of disease with the current chemotherapeutic treatment strategies remains poor. Hence, new agents and molecular targets for gastric cancer therapy are desperately needed. Sphingosine kinase 1 represents a promising novel target for anti-cancer therapy. However, the most common used small molecule inhibitors of SphK are unspecific inhibitors of SphK1. Here we investigated the effect of targeted downregulation of SphK1 by locked nucleic acid antisense oligonucleotides (LNA-ASO) in gastric cancer cell lines.

\section{Materials and methods}

MKN28 and NCI-N87 gastric cancer cell lines were assessed for cell proliferation and cell death electronic cell counting and FACS analysis, respectively. Target modulation of Sphk1 mRNA was assessed by real-time reverse transcriptase PCR. For combination therapy, Sphk1 LNAASO was combined with doxorubicin and analyzed for cell growth and apoptosis.

\section{Results}

LNA-ASO targeting SphK1 reduced SphK1 mRNA levels in a dose dependent manner (1.9-4.9-fold) whereas the control LNA-ASO did not lower Sphk1 mRNA levels at all. We next assessed the biological relevance of SphK1 downregulation by LNA with respect to anti-proliferative activity. Following transfection with $12.5 \mathrm{nM}$ Sphk1 LNA-ASO we observed growth inhibition of MKN28 gastric cancer cells (up to 57\%) beginning from $24 \mathrm{~h}$ after transfection. Notably, the combination of Sphk1 LNA-ASO with doxorubicin resulted in significant chemosensitizing anti-proliferative activity. The anti-tumor activity coincided with an increase in the number of apoptotic cells both in the monotherapy and in the combination group as determined by FACS analysis.

\section{Conclusion}

SphK1 target downregulation induces apoptosis and reduces cell counts of gastric cancer cells indicating a role for SphK1 as a functional relevant molecular target in gastric cancer cells. Moreover, downregulation of SphK1 sensitizes gastric cancer cells to doxorubicin. Our data provide a sound rationale for in vivo studies of SphK1 LNA ASO as novel and promising strategy against gastric cancer. 